\title{
Fraude em avaliações no ensino superior do Brasil: aproximações com uma pesquisa de Portugal
}

\author{
Maria Alzira de Almeida Pimenta \\ Sônia de Almeida Pimenta
}

Resumo: A prática da fraude em avaliações (cola, pesca, fila, no Brasil; copianço, em Portugal) tem aumentado em todo o mundo (ECKSTEIN, 2003). Além de contemplar uma dimensão ética que merece reflexão, ela pode trazer implicações significativas para a qualidade da formação acadêmica dos estudantes e, consequentemente, comprometer a formação profissional. O problema tratado neste artigo é a fraude em avaliações no Brasil e em Portugal. O objetivo é apresentar e analisar resultados de pesquisas realizadas nas IES desses países. A pesquisa bibliográfica fornece suporte para a análise de dados coletados por meio de entrevistas e questionários aplicados a estudantes. A análise e a interpretação dos resultados revelam, além da ampla permanência desta prática nas universidades brasileiras, dentre outros aspectos, diferentes motivações para prática da fraude, as quais não impedem a consideração, por parte daqueles que a praticam, como sendo ruim ou censurável.

Palavras-chave: Avaliação da aprendizagem. Fraude em avaliação. Educação superior.

\section{Exam cheating in Brazilians' universities: similarities with a portuguese research}

Abstract: The practice of exam cheating (cola, pesca, fila, in Brazil; copianço, in Portugal) has increased worldwide (ECKSTEIN, 2003). Besides theethical dimension that merits consideration, this practice can bring significant implications for the quality of student's formation as well as undermining it. The problem addressed in this article is exam's cheating in Brazil and Portugal. The goal is to describe and analyze results of surveys conducted in Higher Education Institutions in these countries. The literature provided support for the analysis of data collected through interviews and questionnaires with students. The analysis and interpretation of the results reveal, beyond the permanence of this wide practice in Brazilian universities, among other things, different motivations for the practice of fraud, which do not prevent the consideration by those who practice it as bad or reprehensible.

Key words: Learning evaluation. Exam cheating. High education. 


\section{Introdução}

A avaliação é um processo determinante no cotidiano das pessoas. Avalia-se desde o clima para escolher a roupa a ser vestida, até o tempo e os recursos a serem investidos em um novo projeto. A avaliação também é fundamental no processo de ensino-aprendizagem e, consequentemente, na prática pedagógica. Esta, por sua vez, é uma prática social, cuja função é educar, ou seja, possibilitar a humanização, a socialização e a individuação que ocorre quando o educando se apropria dos saberes e práticas construídos pela humanidade. É sabido que a conjuntura social e suas contradições influenciam a prática pedagógica. É na interface do tecido social com o ambiente educativo que a fraude em avaliações se instaura, associada a um conjunto de determinantes históricos, culturais e, por isso, sociais que nos impelem a vê-la como um fenômeno complexo e desafiante.

Nos estabelecimentos escolares, desde a Educação Infantil até as Instituições de Ensino Superior (IES), a qualidade do processo de ensino-aprendizagem e o desempenho dos alunos são avaliados. A delicada e complexa tarefa de avaliar envolve competência e responsabilidade em relação à formação humanística, cidadã e profissional dos estudantes. Entretanto, apesar de sua importante função no processo de ensino-aprendizagem, a avaliação ainda é objeto de desconforto por parte de professores e estudantes e de preocupação para pesquisadores. Isto se dá porque, apesar de servir para melhorar a aprendizagem quando informa sobre a adequação da metodologia (ensino), ela tem sido usada como instrumento de classificação e de discriminação. Cumpre ressaltar que ao melhorar o ensino e a aprendizagem, melhora a satisfação do professor com seu trabalho.

A vasta produção bibliográfica sobre avaliação aborda desde a evolução da teoria: conceito, características, pressupostos, função, procedimentos etc. (SOUSA, S., 1991), até propostas de como ela pode servir para melhorar a aprendizagem dos alunos (BALLESTER et al., 2003), passando pela pesquisa sobre avaliação do rendimento escolar (SOUSA, C., 1991) e a crítica da produção brasileira na área (FREITAS, 2002).

Durante o processo de formação, o estudante tem a experiência de ser avaliado - o que envolve tensão emocional, pois a nota, resultado da avaliação, costuma estar associada a uma identidade: mau aluno, bom aluno, inteligente etc.. Entretanto, em geral, a diversidade de aspectos envolvidos nesse processo tão estressante e determinante para sua vida acadêmica e profissional é desconhecida.

Como exemplo de aspectos que influenciam na prática da avaliação, é possível citar: as concepções de avaliação (QUINQUER, 2003), os critérios e procedimentos utilizados e a adequação destes aos contextos educacionais 
(CARDOSO, 1999; JORBA; SANMARTÍ, 2003; LUCKESI, 2003; FERNANDES, 2006). As concepções determinam os critérios e procedimentos que, por sua vez, são adequados, ou não, a uma determinada situação de aprendizagem. Parte-se do pressuposto de que a avaliação pode identificar como a aprendizagem está acontecendo e o que precisa ser alterado na prática pedagógica para a melhoria da qualidade do ensino. Essa função diagnóstica, assumida em uma perspectiva de avaliação formativa é defendida - com algumas variações e acentos em aspectos distintos - por Perrenoud (1999, 2000), Vasconcellos (1993), Hadji (2001) e Fernandes (2006), entre outros. Entretanto, sabe-se que no cotidiano das IES brasileiras (e de outros países, também) a avaliação tem, preponderantemente, a função de verificar e classificar a aprendizagem em notas ou conceitos que servem para a classificação, seleção e certificação dos estudantes.

Tendo como premissa a relevância da avaliação para a qualidade do processo de ensino-aprendizagem, este artigo aborda a prática da fraude de estudantes em avaliações, tais quais: provas, exercícios, trabalhos etc.. Para tanto, apresenta os resultados de duas pesquisas que, embora tenham o mesmo objeto, como era de se esperar, partem de contextos e objetivos distintos, mas apresentam vários aspectos convergentes que permitem ampliar a visão sobre o fenômeno estudado. A pesquisa brasileira foi realizada nos estados de São Paulo, Minas gerais e Paraíba, respectivamente nos anos de 2007-2008, 2010 e 2011. A outra, desenvolvida em Portugal entre 1997 e 2003, teve seus resultados divulgados no livro "O Copianço na Universidade: o grau zero na qualidade", de Ivo Domingues.

A fraude em avaliações é comumente chamada de cola, pesca, fila etc. termos usados no Brasil - e copianço, em Portugal. Observa-se que os termos usados nos dois países apresentam-se isentos de valoração, uma vez que estão focados no ato, sem alusão aos aspectos relacionais e às implicações do ato. Entendemos que a fraude acadêmica envolve aspectos relacionais que dizem respeito à relação que o estudante estabelece com o professor, com a instituição, em que estuda, e com as normas estabelecidas por ela. Com respeito às implicações do ato, ou seja, implicações da prática da fraude, dentre elas, destacamos a probabilidade da aprendizagem não ter ocorrido, pois, caso contrário, a cola seria desnecessária.

Diferentemente, o termo usado em publicações estrangeiras (EUA, Grã-Bretanha etc.) é cheating, cuja tradução literal é traição, burla e remete a uma valoração e ao que chamamos aspectos relacionais.

Um levantamento bibliográfico realizado em bancos de dados convencionais e virtuais 1 permite afirmar que o tema "cola" foi pouco pesquisado, no

1 No Scielo (Scientific Eletronic, Libraly Online), importante banco de dados de acesso aberto, por exem- 
Brasil, indicando, provavelmente, o distanciamento ou, ainda, pouca valorização do tema por parte de pesquisadores das ciências da educação, as quais estão implicadas com o fenômeno. Entretanto, em outros países 2 há uma vasta produção de pesquisa, o que indica a preocupação com o mesmo.

Outro tipo de fraude bastante praticada é o plágio - cópia de textos e de trabalhos, em geral (projetos, relatórios, Trabalhos de Conclusão de Curso, dissertações etc.), na íntegra ou em parte, sem fazer referência ao autor. Há, por parte de quem pratica a fraude (traição/burla/ cola/plágio), uma percepção de que está transgredindo, cometendo um equívoco e incorrendo em uma ilegalidade. Mas há, por outro lado, uma glamorização, principalmente quando a fraude é considerada inócua, sobretudo a praticada nas escolas. Existem vários sites3 e textos disponíveis na internet em que os estudantes tratam de forma jocosa as estratégias que utilizam para burlar as avaliações.

A fraude, de uma maneira geral e nos processos educativos em particular, sendo um objeto de pesquisa complexo, demanda uma abordagem multidisciplinar para qual a Sociologia, a Filosofia, a Psicologia e o Direito, dentre outras disciplinas, podem contribuir para sua compreensão. A discussão da fraude interessa a muitas áreas da convivência humana, particularmente, à área de educação por sua relação com a avaliação, com o processo de ensino-aprendizagem e com a construção de conhecimento.

Há várias questões, a respeito da prática da fraude, que ainda necessitam ser respondidas. Elas dizem respeito à avaliação e ao perfil de estudante e de professor. Dentre elas, destacamos as seguintes: qual a relação entre a prática da cola e a adequação do instrumento de avaliação? Qual a influência do perfil do professor (domínio do conteúdo, adequação didática, coerência entre objetivos, método e forma de avaliação, o modo como trata os momentos de avaliação com menos exigência ou rigidez)? Em qual faixa etária, ou série, se inicia a prática da fraude? É uma prática coletiva ou individual? Qual a relação entre a incidência de cola e as disciplinas ou áreas de conhecimento? Qual a proporção de estudantes que a utilizam? Quais as motivações ou justificativas destes estudantes para praticar a fraude?

plo, foi encontrado somente um artigo baseado em pesquisa realizada no Brasil (SILVA et al., 2006), indicando a escassez de pesquisas sobre o tema.

2 A maior produção de pesquisas sobre o tema, realizadas em Universidades (GREEN, 2004; KLEIN, 2007; LAWSON, 2004), instituições independentes (CANNELL, 1989) e estatais (MARAMAK; MALINE, 1993) ocorre nos Estados Unidos da América. Mas também há pesquisas em países como Kirguistão (NURJOLBER, 2008).

3 No YouTube, há vídeos que ensinam técnicas para colar (em How to cheat on any test); há um chat explicando como colar em <http://br.answers.yahoo.com/question/index?qid=20060818190643AAenH DI>; e ainda em <www.perguntascretinas.com.br/2008/04/22/como-colar-na-prova-manual-da-cola/ $>$. Todos acessados em 15 maio 2010. 
Para responder a estas perguntas faz-se necessário que este fenômeno seja enfrentado cientificamente, não banalizado ou como algo que se sabe que existe, mas que ninguém quer tratar. Para tanto, será necessário que mais pesquisadores se debrucem sobre esse objeto incômodo e constrangedor.

Para efeito deste artigo, apresentaremos apenas os dados relativos às questões que apresentam similitudes com a pesquisa desenvolvida por Domingues (2006) em Portugal, considerando o nosso propósito, qual seja o de refletir sobre o fenômeno da fraude nas instituições de ensino superior e as motivações para sua prática. Este procedimento se justifica na medida em que entendemos que a compreensão de um fenômeno que nos é familiar se enriquece na medida em que podemos refletir sobre a sua configuração em outros contextos, compreendendo, a partir das diferenças, os modos como esta configuração ocorre.

\section{As pesquisas no Brasil e em Portugal aqui discutidas}

A pesquisa desenvolvida no Brasil pelas autoras deste artigo teve como orientação a pergunta "O que leva os alunos a praticarem fraude em avaliações?". Esse questionamento se justifica em função da avaliação ser parte fundamental do processo de ensino-aprendizagem. Se ela ocorre de maneira fraudulenta, o processo de Ensino-Aprendizagem fica comprometido e, consequentemente, também comprometida fica a qualidade da formação e a qualificação para a vida profissional. Os pressupostos da pesquisa consideraram que a prática da fraude acontece porque a) os objetivos, métodos e avaliação estão inadequados à atual conjuntura educacional; b) o conhecimento não é valorizado como um bem individual; e c) a dimensão ética inerente ao processo de formação do ser humano tem sido desconsiderada pela comunidade acadêmica, na medida em que a fraude tem sido pouco investigada.

Para tanto, os objetivos foram os que seguem: descrever e analisar a prática da cola em IES brasileiras; e identificar por que as pessoas colam e os mecanismos de sua instauração enquanto prática. Para atingir esses objetivos foi necessário analisar: o fenômeno, a extensão, a visão dos envolvidos e os elementos culturais. A metodologia seguiu uma abordagem qualitativa considerando a exigência de que "... o mundo seja examinado com a idéia de que nada é trivial, que tudo tem potencial para constituir uma pista que nos permita estabelecer uma compreensão mais esclarecedora de nosso objeto de estudo." (BOGDAN; BIKLEN, 1994, p. 49). Na pesquisa bibliográfica, foi realizada uma revisão sobre o tema da fraude em avaliações e, na pesquisa de campo, os estudantes preencheram um questionário com perguntas fechadas e abertas, e responderam 
uma entrevista. As perguntas do questionário procuravam identificar em quais situações o aluno colava; sua motivação para a cola; sua visão sobre a prática da cola e o que vislumbrava como possíveis consequências da prática.

Para efeito deste artigo, apresentamos parte dos dados do questionário realizado com estudantes de Cursos de Ciências Humanas de Instituições de Ensino Superior da rede privada, dos Estados de São Paulo, Minas Gerais e Paraíba. A amostra constituiu-se de 250 respondentes. Este número corresponde aos alunos presentes nos dias de preenchimento dos questionários nas turmas pesquisadas das IES. A participação foi voluntária e as pesquisadoras garantiam o anonimato, pois os questionários eram aplicados na sala de aula e, ao serem entregues pelos alunos, eram dobrados e misturados. Aos respondentes cabia apenas identificar sua idade e seu curso. Esses procedimentos, que sabidamente por nós, impossibilitavam a caracterização de um perfil sócio-demográfico4 dos sujeitos, foram definidos para permitir que os estudantes se expressassem sem receio de represálias, hipótese cogitada por eles, frequentemente, quando explicávamos sobre o que se tratava a pesquisa. Apresentamos também fragmentos das entrevistas realizadas com estudantes dos cursos citados, de março a junho de 2009, de modo a enriquecer a reflexão sobre os dados do fenômeno apresentados na pesquisa realizada no Brasil e em Portugal.

A pesquisa sobre o tema Fraude acadêmica conduzida por Domingues (2006) em uma universidade pública portuguesa consistiu de um estudo de caso, com uma abordagem qualitativa e quantitativa. Na primeira, foram realizadas entrevistas semi-estruturadas com 40 estudantes e 20 professores, no período de 1997 e 1998. Na segunda, ocorrida durante os anos de 2001 e 2003, os dados foram coletados por meio de questionários respondidos por estudantes, em uma amostra não probabilística, totalizando 1177 questionários válidos. Atuando na área de sociologia das organizações, o pesquisador Ivo Domingues escolheu a prática da cola para seu estudo por considerá-la o "mais fiel indicador da eficácia e da eficiência dos processos de avaliação e da organização normativa das condutas docentes e discentes." (DOMINGUES, 2006, p. 10). Como resultados de sua pesquisa, são descritas as formas de fraudar; as atitudes de estudantes e professores frente à prática e uma análise da relação entre a prática da fraude e as práticas de controle social.

Domingues (2006) relacionou os efeitos negativos da fraude em avaliações com o enfraquecimento da empregabilidade dos egressos, o que implica em transposição dos custos de formação acadêmica para as empresas empregado-

4 Jordan (2001) compara estudos sobre fraude acadêmica e conclui que as tentativas de definir um perfil dos praticantes, considerando gênero e idade, resultaram inconsistentes. 
ras. Ainda como desdobramento desse tipo de fraude, o autor considera que por meio da socialização institucional são favorecidas práticas de infidelidade normativa. Estas, por sua vez, fomentam a cultura da permissividade, ao invés da cultura do rigor, reduzindo a competitividade das empresas e, na mesma proporção, as possibilidades de sucesso do país.

\section{Apontamentos sobre os resultados das pesquisas no Brasil e em Portugal}

Ao analisar o fenômeno da "cola", a partir da aproximação das pesquisas realizadas no Brasil e em Portugal, consideramos cinco categorias: frequência, condição, motivação, visão, consequências.

\section{a) Frequência}

Dentre os respondentes da pesquisa brasileira, em torno de $67 \%$ assumem que colam, $27 \%$ dizem que não colam e $6 \%$ se abstiveram de um total de 250 alunos. Os respondentes portugueses, segundo Domingues (2006), 46\% dizem ter colado de papéis preparados por si mesmo e $71 \%$ revelam ter colado a partir de colegas a quem pediram ajuda5. Os dados coletados apontam para o fato de a prática da cola ter se tornado uma prática corriqueira nas IES pesquisadas. Essa porcentagem significativa, em ambos os países, também foi encontrada nos estudos de Whitley (1998), McCabe, Trevino e Butterfield (1996) e Eckstein (2003). Este último confirma o aumento da prática de fraude em todo o mundo, seja em países desenvolvidos ou em desenvolvimento. Segundo o estudo realizado para a UNESCO (ECKSTEIN, 2003), a fraude em avaliações é uma ameaça cara para o funcionamento eficiente e para a confiança da sociedade na reabilitação e na segurança de suas instituições6. Uma das causas imediatas apontadas pelo estudo do aumento da prática de fraudes é o acirramento da competitividade por espaço no mercado de trabalho. O que antes foi tratado como uma infração individual tem se expandido até configurar-se como uma indústria de fraudes. Cumpre ressaltar que essa "indústria” também se beneficia dos avanços tecnológicos da eletrônica, da informática e da comunicação para potencializar suas estratégias.

5 Os alunos podiam escolher mais de uma resposta implicando em um total com mais de $100 \%$.

6 O artigo de Paulsen (2009) chama a atenção para o fato de a confiança, no âmbito da economia, ser descrita como uma geradora de vantagens em arranjos sociais, promovendo desenvolvimento e baixando os custos dos contratos e transações. 


\section{b) Condição}

As respostas que expressam a condição em que era usada a cola: "sem média", "professor não controlava" e "não estudou" somam 28 \% e são contingenciais, ou seja, não dizem respeito à sua formação anterior ou ausência de pré-requisitos. Mas, estão relacionadas às condições de tempo, motivação e organização para o estudo; ao cuidado do professor em manter a lisura do processo. Consideramos que o fenômeno da cola também pode estar associado à prática de avaliação classificatória. Nesta, a qualidade da aprendizagem é traduzida em uma nota que constará no Histórico Escolar.

Este aspecto foi tratado por Lima (1997) ao observar que a Universidade tem se enquadrado em um modelo de educação contábil que privilegia os aspectos mensuráveis da avaliação, focando o resultado (produto) e não o processo. Corroborando com essa visão, Dias Sobrinho (2002) ressalta que a avaliação tem servido como um instrumento dos governos para implantação de uma cultura generalista e fiscalizadora quando é realizada para prestação de contas e controle. Esse modelo é bastante adequado à demanda por certificação que interessa aos alunos para ingressarem no mercado de trabalho e aos governos para cumprirem metas associadas a financiamentos de órgãos de fomento e desenvolvimento. Nesse contexto em que a aprendizagem não é prioritária, a formação propriamente dita torna-se secundária.

\section{c) Motivação}

A motivação dos estudantes brasileiros para a prática da cola foi identificada a partir da situação em que era mais comum fazer uso dela. Segundo os dados coletados, a "prova difícil" foi a justificativa com maior incidência (45\%). As provas das "disciplinas que estavam sem média para aprovação" também tiveram uma incidência significativa (10\%) junto com a resposta "outras". Estas referiam-se a situações em que o estudante não estudou e, sentindo-se, portanto, despreparado, passa a considerar a cola uma saída para suprir sua deficiência. Com incidência um pouco menor, aparecem as situações "provas em que o professor não controlava" e as "listas de exercício". O fato de a maioria dos estudantes que colam justificar seu ato a partir da percepção de que as provas são difíceis poderia indicar: uma inadequação do instrumento de avaliação (por exemplo, o professor exige na prova o domínio de um conteúdo que não foi trabalhado, em sala de aula); ou a falta de pré-requisitos por parte dos estudantes (hipótese considerada na pesquisa realizada no Brasil). É público o baixo desempenho dos brasileiros em avaliações, o que pode revelar problemas de 
aprendizagem. Waiselfisz (2007) adverte que um dos pontos frágeis da educação dos jovens brasileiros está na qualidade do ensino e da aprendizagem. Após analisar os resultados do PISA (Programa Internacional de Avaliação de Alunos) de 2000 a 2006, conclui que Tanto o PISA quanto o Sistema de Avaliação do Ensino Fundamental - SAEB são contundentes ao afirmar a baixa qualidade das aprendizagens escolares e sua persistência imutável no tempo.

A atitude permissiva do professor é apontada em várias pesquisas como um fator estimulador da cola. Essa relação entre permissividade e fraude pode ser explicada pela observação de Mizukami (1996, p. 60):

[...] o professor é o principal mediador entre os conhecimentos socialmente construídos e os alunos. É ele, igualmente, fonte de modelos, crenças, valores, conceitos e pré-conceitos, atitudes que constituem, ao lado do conteúdo específico da disciplina ensinada, outros tipos de conteúdos por ele mediados.

Ou seja, se o professor se isenta de defender o valor da transparência e da lisura do processo em que o estudante expõe seus conhecimentos, é provável que ele não seja considerado. Some-se a essa observação, a análise de Aragão (2002, p. 12) sobre a avaliação:

[...] de modo geral, a prática mais frequente por parte de professores - principalmente entre os professores universitários - é encaminhada, quase que exclusivamente, para a retenção, por parte dos alunos, de enormes quantidades de informações passivas, com o propósito de que sejam memorizadas, evocadas e devolvidas - nos mesmos termos em que foram apresentadas - na hora dos exames, através de provas, testes, exercícios, mecânicos ou repetitivos, quero dizer, sem compreensão. Em uma prática assim caracterizada, há poucos indícios de que o ensino possa visar à compreensão do aluno.

Essa descrição, sabidamente observável em estabelecimentos de ensino tanto de Educação Básica quanto de Ensino Superior do Brasil, corresponde ao que Freire $(1974,1996)$

denominou de educação "bancária”. Se o professor tem uma prática assim caracterizada e dificuldade de defender alguns valores, o que pode ser associado a certo descompromisso, não levaria o estudante a ter a mesma atitude? A prática da fraude não seria a manifestação desse descompromisso?

Recentemente, a mídia tem atribuído à má formação do professor a causa do fracasso da educação7. Culpar o professor, além de desconsiderar a complexida-

7 Em entrevista recente, o economista Martin Carnoy, autor do livro "A Vantagem Acadêmica de Cuba", 
de da questão, aproxima-se de um reducionismo maniqueísta. É frequente haver muitos estudantes em sala (dezenas), o que dificulta ao professor acompanhar sua aprendizagem. Para atendê-los, as provas objetivas são as mais utilizadas e, por sua vez, não estimulam o desenvolvimento da habilidade de escrever. Em grande parte das IES privadas, os professores recebem pelo número de aulas dadas, mais 20\% sobre essa quantidade, para preparação e correção de atividades. Sendo assim, a remuneração do trabalho que necessita ser feito fora da sala para garantir a qualidade do processo de ensino-aprendizagem se reduz sempre a este percentual, mesmo se consumir um tempo maior, o que implica em sua desqualificação. Zeichner (1993, p. 16) defende o protagonismo dos professores na educação ao afirmar que “... devem desempenhar um papel ativo na formação tanto dos propósitos e objetivos do seu trabalho, como dos meios para os atingir; isto é o reconhecimento de que o ensino precisa voltar para as mãos do professor".

Na pesquisa de Domingues (2006), foram identificadas várias motivações para a prática da cola. Uma delas é a consideração do copianço como estratégia de nivelamento (pois quem copia acaba tendo tanta chance no mercado de trabalho, quanto quem estuda). Outra motivação citada foi a necessidade, quando o estudante alega que não houve preparação (horas de estudo) adequada. E ainda, o descuido do professor é apontado como facilitador da cola - esta última semelhante ao que acontece, no Brasil, em menor proporção. Entretanto, a justificativa (motivação) para a prática da cola com maior incidência foi facilitar ou garantir o sucesso escolar. Domingues (2006) observa que essa motivação é resultado da função certificadora da universidade e oculta o fracasso do processo formativo. Essa observação também cabe à realidade brasileira uma vez que a prática da cola traveste a não aprendizagem dos estudantes em aprendizagem. Eles ficam em condições de obter a certificação de curso superior sem necessariamente ter obtido a formação acadêmica e profissional adequadas.

É possível observar aspectos relevantes nas diferentes motivações alegadas por estudantes brasileiros e portugueses. Os primeiros apresentam como motivação algo imediato: a prova difícil, já os portugueses têm uma perspectiva mais ampla: a do sucesso escolar e, portanto, menos imediata. Essas diferentes perspectivas remetem à prática da fraude como uma estratégia de amplo espectro, pois ela tem sido usada como solução em situações diversas.

declarou em entrevista a Frias e Bencini (2009): Os melhores professores no Brasil têm em média desempenho abaixo da média do professorado de países desenvolvidos. Investir e melhorar a escola pública, que é a base de comparação dos pais, elevaria o resultado das melhores escolas particulares também. Professores são bons em pedagogia, mas não no conhecimento a ser ensinado. Não treinam muito matemática e não sabem como ensiná-la (grifo nosso). 


\section{d) Visão}

Na pesquisa brasileira, há uma pergunta específica8 sobre como os estudantes qualificam a cola. Foi observado que, aproximadamente, $53 \%$ dos estudantes consideram-na "ruim". Somando-se com a parcela que considera "censurável" (28\%) chega-se a $81 \%$, ou seja, é possível inferir que a maioria dos estudantes tem uma visão negativa da cola. É interessante constatar que essa porcentagem é próxima dos que admitem usar a cola. Apenas 12\% veem a cola como "necessária" e uma pequena parcela a percebe como "positiva" (2\%). Na pesquisa realizada em Portugal, os estudantes, em geral, também identificam a fraude como ilícita e desonesta, mas a praticam alegando que é pouco punida e porque preferem mais os benefícios que permite a respeitar a regra que a interdita.

Outra perspectiva que a fraude em avaliações - em suas diversas manifestações - poderia ser pensada é quanto a sua dimensão ética e moral. Aristóteles pensava a ética como o que leva a busca da felicidade e do bem comum (ARISTÓTELES, 2011). La Taille (2008), ao diferenciar moral de ética, considerou que a primeira responde a pergunta "como devo agir?" - remetendo às regras e às normas. A ética, por sua vez, está relacionada às perguntas: como viver? Quem eu quero ser? Cujas possíveis respostas remetem a valores, sentidos e significados.

Savater (2002) e Vazquez (2012) apresentam semelhanças ao distinguirem moral e ética. Para eles, a moral é o conjunto de normas e comportamentos que a sociedade aceita como válidas. A ética é a reflexão sobre esse conjunto de normas, considerando sua validade ou comparando-o com os de outras sociedades. Assim, a ética está relacionada ao que motiva e orienta o comportamento humano. Motivos que, sendo diversos, torna difícil determinar o que é certo ou errado. Desta forma, é possível que a fraude em avaliações seja vista, por alguns estudantes, como um recurso ético, ainda que imoral para alcançar o resultado esperado. O que parece tornar-se um fato menor, tanto para os estudantes/cidadãos quanto para os responsáveis pela educação, é a forma e a qualidade desse resultado.

\section{e) Consequências}

Como consequências da cola, $67 \%$ dos estudantes brasileiros responderam que deixam de "aprender o conteúdo", indicando que a maioria entende que seu uso implica uma falta de aprendizado. Os demais estudantes se dividem

8 Na pesquisa de Domingues (2006), não há pergunta específica sobre como os estudantes qualificam o copianço; 
entre considerar que a cola não traz consequências (13\%) ou apontam outras (Outras - 13\%).

Na opção "outras", o estudante é então levado a nomear a conseqüência para a prática da cola. Dentre as apontadas, chamam a atenção: "Despreparo para o mercado de trabalho" e "Não pagar DP (dependência)". A primeira revela uma compreensão de que a formação acadêmica faz parte da formação profissional e, se uma é deficitária, ocorre o comprometimento da outra. A segunda resposta revela que é possível a existência de uma naturalização do ato de colar, associado ao imediatismo, que parece ser assim formulado: "colo, sou aprovado, não preciso pagar DP”. Essa atitude coloca em questão como o sujeito que "cola" lida com as dificuldades e os desafios? Se um problema é resolvido agora (ficar de DP) de maneira fraudulenta, quais as competências e habilidades estão sendo desenvolvidas para lidar com os problemas do futuro?

Como já observado no início do texto, uma consequência da cola (dentre as mais importantes) apontada por Passow (2006) e que afeta diretamente o processo de ensino-aprendizagem, é o fato de ela mascarar a avaliação, impedindo que o professor efetivamente conheça o que os alunos aprenderam ou não, o que precisa ser retomado ou já foi aprendido. Sem a função de informar sobre o aprendizado dos estudantes, situando o professor sobre como conduzir seu trabalho, a avaliação adquire o caráter exclusivamente classificatório (LUCKESI, 2003), dentro de uma perspectiva de educação "bancária" (FREIRE, 1974, 1996).

Enquanto os estudantes brasileiros apontaram para consequências de natureza mais imediata, os estudantes portugueses consideram em proporções praticamente iguais que a prática da cola degrada a formação moral dos alunos, afeta negativamente a preparação para o bom desempenho profissional e tem um lado positivo: torná-los mais hábeis e flexíveis em situações difíceis.

Domingues (2006) identifica, nas respostas, uma dicotomia entre o pensamento e a ação. Essa dicotomia estaria relacionada a dois planos distintos: o discursivo, que envolve o juízo ético e o prático, que determina a ação. No primeiro, estão em jogo os princípios fundamentais à ordem social e no segundo os interesses e objetivos imediatos. A grande incidência da prática da cola estaria relacionada ao fato de, no momento de ação, os interesses materiais se sobreporem ao juízo ético. Para o estudante, as consequências positivas da prática da cola são mais rapidamente observáveis do que as negativas. Privilegiar as vantagens imediatas, ou seja, desconsiderar as consequências negativas torna-se determinante na prática da cola.

Callahan (2004) apresenta outra visão sobre o porquê praticar a cola, mesmo considerando-a censurável. Segundo o autor, os estudantes que colam nas 
avaliações falam de seu medo de um fracasso econômico e da falta de empenho dos professores de cobrarem uma atitude ética. Segundo esse autor, a difusão de comportamentos antiéticos provocados pelas mudanças sociais e econômicas está redesenhando os valores pessoais. Além disso, ao contrário do que se acredita, esses comportamentos antiéticos não têm origem no individualismo radical dos anos 1960, mas sim na obsessão pelo dinheiro dos anos 1980 e 1990, fragilizando o senso de comunidade e de responsabilidade social e aumentando a ganância e o materialismo, tornando a competição mais acirrada.

Giddens (1991) contribui para a compreensão de como as mudanças sociais e econômicas têm influenciado valores e comportamentos ao ressaltar as profundas ligações entre a modernidade e as transformações do tempo e do espaço. Na pré-modernidade, a vida social era marcada pela "presença", o que mantinha a coincidência de tempo e espaço. Na modernidade, a ausência é instaurada na vida social na medida em que é possível relacionamentos distantes, virtuais. O processo de separação entre tempo e espaço é que garante o dinamismo da modernidade e o processo de desencaixe. Este último considerado por Giddens (1991, p. 29) como “... o 'deslocamento' das relações sociais de contextos locais de interação e sua reestruturação através de extensões indefinidas de tempo-espaço". Esse fenômeno promove várias mudanças, dentre elas a flexibilização das restrições dos hábitos e das práticas locais. Essa flexibilização pode explicar o aumento da incidência de fraude em avaliações.

A pulverização das relações sociais no tempo e no espaço poderia gerar um descompromisso que funcionaria como um aval para esse tipo de fraude. Giddens (1991) cita dois mecanismos de desencaixe: as fichas simbólicas e os sistemas peritos. O dinheiro, enquanto exemplo de ficha simbólica, serve para troca independentemente das características específicas dos indivíduos ou grupos que o usa em qualquer conjuntura particular.

Já os sistemas peritos consistem de “... sistemas de excelência técnica ou competência profissional que organizam grandes áreas dos ambientes material e social em que vivemos hoje" (GIDDENS, 1991, p. 35). São esses sistemas que legitimam a atuação de profissionais necessários - professores, médicos, advogados, engenheiros etc. - e contratados pelas pessoas leigas. Às pessoas comuns não cabe checar a competência de cada profissional. Elas confiam que, se o profissional possui uma certificação, também possui competência para o exercício de sua profissão. A confiança torna-se, portanto, uma das bases das negociações de serviços de profissionais. Entretanto, como confiar na competência e na postura ética de um profissional que, durante sua formação, obteve aprovação fraudando suas avaliações? 


\section{Com a palavra, os estudantes}

Alguns dos depoimentos coletados por meio de entrevistas permitem fazer inferências sobre de que maneira os estudantes pensam os vários âmbitos que envolvem a prática da fraude, no Brasil e em Portugal. A estudante J (IES privada, $1^{\circ}$ semestre) afirma: Não concordo com a aplicação de prova, pois ela não consegue avaliar se o aluno sabe ou não, então colo. Diante da questão: Se você não concorda, burla? A resposta foi: sim. O depoimento de um estudante português é bastante semelhante (DOMINGUES, 2006, p. 33): a maneira como as coisas são leccionadas e a maneira como os testes são feitos é quase como um estímulo para as pessoas copiarem. Esses estudantes parecem considerar tal comportamento legítimo partindo do pressuposto que a prova não é um instrumento adequado de avaliação. É interessante observar que essa visão lhes permite uma "solução fácil" diante da situação de desconforto e dificuldade gerada, neste caso, pela prova. Entretanto, faz-se necessário questionar a segurança com que julgam a inadequação da prova; se não é esse julgamento um pretexto para burlar ("solução fácil") e, ainda, se essa visão (pretexto) não se repete em outras situações, valendo-se da mesma lógica e implicando outras formas de burla.

O Estudante M (IES privada, $1^{\circ}$ Semestre) aborda a cola por um viés comportamental/cultural: no Brasil, tem uma coisa que eu adoro: tudo tem jeito e as pessoas dão jeito, "acochambrado", "por baixo dos panos", do jeito que dá, mas resolve. A cola é uma manifestação desse jeito. Nessa visão, a prática da fraude está associada ao "jeitinho brasileiro" (DAMATTA, 1986) que ora expressa a criatividade e a flexibilidade do cidadão comum e ora serve para justificar seus pequenos "deslizes" de conduta no enfrentamento dos problemas do cotidiano. O discurso foi incorporado e aceito quase como um dado natural, inquestionável e até positivo e que é utilizado a favor de uma maneira de pensar a sociedade. Na pesquisa de Domingues (2006), a cultura também serve de justificativa para a prática da fraude, como é possível perceber no depoimento do estudante: eu acho que se copiou desde sempre e, naturalmente, é provável que se vá copiar sempre. Copiar já está muito inscrito na cultura dos alunos, desde que entram na escola (grifo nosso). (p. 187). O estudante refere-se a uma cultura dos alunos, que provavelmente é análoga à cultura dos adultos, da sociedade, que Domingues (p. 186) chama de subcultura estudantil. Gomes (2008, p. 150) confirma a visão da prática da fraude ligada a aspectos culturais:

Com efeito, muitos alunos foram formados nesse autêntico currículo oculto da escola que é a aprendizagem da 'arte' de contornar as regras 
e os valores oficiais que regem o processo de avaliação, independentemente de aquelas e estes terem, ou não, sido objecto de um tratamento formal, por exemplo, sob a forma de regulamentos. Em consequência, muitos alunos chegam ao ensino superior 'perfeitamente' formados na ideologia, nos discursos, nas técnicas e nas 'artes' da fraude e do 'copianço', práticas nunca questionadas, pois, é muito provável que, ao longo do seu percurso escolar, nunca tenham sido confrontados com discursos e práticas de des-legitimação da fraude, que pusessem em evidência as suas implicações ético-morais, académicas e sociais, com excepção de determinadas situações. Dados de investigação oferecem indicações de que a fraude e o copianço constituem uma prática generalizada, naturalizada e banalizada no espaço escolar.

Segundo o depoimento da Estudante N (IES privada, $2^{\circ}$ semestre) a cola é: uma forma de cooperação. Quem sabe ajuda quem não sabe tanto. Reforça os laços de amizade. Na pesquisa realizada em Portugal, a relação entre prática de fraude e solidariedade é expressa na crítica aos que denunciam os colegas que colam e aos que não "passam cola" como é possível observar nos seguintes depoimentos: a) se alguém fizesse uma denúncia, os colegas reagiriam muito mal. Esse aluno ficaria de parte, deixaria de ser nosso amigo; e b) guardar apontamentos é mais grave, é ridículo. Não dão hipóteses aos outros que podiam estudar pelos mesmos apontamentos. Estamos na Universidade, devemos ajudar uns aos outros. Essa visão é compartilhada pelos estudantes que participaram da pesquisa de Silva et al. (2006). Estes autores asseveram que a prática da cola envolve questões de altruísmo, porque o estudante, ao praticar esse tipo de ação, está reagindo à situação de dificuldade de um colega, procurando atenuá-la e, a princípio, não visa o interesse próprio (SILVA et al., 2006). Também destacam que envolve uma transgressão, embora a visão da maioria dos estudantes que fizeram parte destas pesquisas remeta positivamente a favor da cola, portanto da fraude, e que tem muitos adeptos que se baseiam em diversos argumentos.

Cumpre ressaltar, aqui, que considerada a delicadeza do tema e o cuidado para evitar uma postura moralista, questionamos se essa visão dos estudantes simplificaria o problema e suas várias nuances, privilegiando a dimensão de socialização, somente. E, ainda, se essa visão promoveria a glamorização da fraude. Suscitamos essa possibilidade considerando que, no Brasil, é muito frequente a criança e o adolescente estudiosos - que, consequentemente, "tiram boas notas" - serem depreciados com tratamentos como: geninho, nerd, CDF ( sigla de expressão bastante chula) e, muitas vezes, isolados do grupo. Coleman (1959), em estudo desenvolvido ao longo de dois anos sobre o "clima de 
valores" em nove escolas públicas americanas, observou que a organização da vida escolar não incentivava a aprendizagem na adolescência. Para os estudantes de todas as escolas pesquisadas, ter uma "boa aparência" e "ser atlético" eram mais importantes que ter "boas notas" e "ser inteligente". Neste contexto, era previsível que os estudantes não valorizassem o desempenho escolar e quem tivesse sucesso na aprendizagem. Os resultados da pesquisa de Coleman (1959), distantes no tempo e no espaço, parecem bastante semelhantes ao que se observa em nossas escolas.

No ensino superior, quem investiu seu tempo estudando poderia passar cola para conquistar o pertencimento ao grupo ou mesmo por sentir-se coagido pelos demais. Também merece ser questionado: criar laços de amizade e praticar a solidariedade demandam ou justificam a prática de fraude nas avaliações?

Diante das respostas dos estudantes dos dois países, é possível considerar que quem usa a cola o faz pensando que não é bom fazer, ou seja, possui uma percepção de que está se prejudicando, mas ainda assim, faz. Fato é que não há consenso sobre tema tão importante.

\section{Como a fraude em avaliações compromete a qualidade da educação}

Segundo Domingues (2006), ao compararem o risco de serem descobertos e o custo da oportunidade de colar com sua necessidade de obter boas notas, os estudantes consideram mais vantajosa a prática da fraude. Isto acontece porque desconsideram o valor da moral e detêm um repertório de experiências, suas ou transmitidas por colegas, em que as práticas de controle dos professores são frouxas ou inexistentes. Os professores, por sua vez, convocam pouco a moralidade e a ética como balizadoras do processo de avaliação. Dos que convocam, uma parte o faz de maneira somente ritualista, outros, com perspectiva mais consequente, ameaçam com punições como cancelamento da prova. Essa dinâmica entre professores e estudantes em torno da fraude foi considerada por Domingues (2006, p. 179) semelhante à relação entre "polícia" e "ladrões".

Outro aspecto que chama atenção, em sua análise, é o pacto de silêncio entre todos os envolvidos nessa dinâmica, cuja função é proteger a prática desviante (DOMINGUES, 2006, p. 167) e considera associado à hipocrisia organizacional. Esta, por sua vez, está presente "... sempre que a acção se rege por umas normas e o discurso por outras, quando as decisões e as ações não são convergentes, quando a organização diz fazer uma coisa e faz outra” (BRUNSSON, 1989 apud DOMINGUES, 2006, p. 152). 
Concordando com a pertinência de sua análise e refletindo sobre os dados coletados no Brasil, entendemos que o caráter controlador e hipócrita, que acaba prevalecendo nas relações entre a IES (representada pelos professores) e estudantes, dificulta que estes sejam parceiros em uma relação que favoreceria a qualidade do processo de ensino-aprendizagem e, consequentemente, da educação.

\section{Considerações finais}

As reflexões aqui realizadas partem das aproximações e semelhanças entre as pesquisas realizadas, no Brasil e em Portugal. Ambas abordam o mesmo problema, a fraude em avaliações, quantificando os praticantes e não praticantes; as motivações dos estudantes para essa prática; e a visão que têm sobre suas conseqüências. A preocupação com os desdobramentos quanto à formação acadêmica e profissional dos estudantes também foi considerada nas duas pesquisas.

A revisão bibliográfica possibilitou às pesquisadoras uma compreensão da fraude em avaliações como um fenômeno complexo, que permite, e carece, de abordagens segundo várias ciências: filosofia, direito, psicologia, entre outras. A análise da fraude em avaliações adotada em nossa pesquisa empírica no Brasil visava, antes de tudo, sensibilizar para a relevância desse fenômeno no campo da educação por não encontrarmos referências que atestassem seu enfrentamento. A pesquisa realizada por Domingues (2006) privilegiou a compreensão do fenômeno a partir de determinações institucionais, principalmente, a hipocrisia organizacional, que explica a divergência entre o que se fala e o que se pratica.

A análise e a interpretação dos dados coletados nas duas pesquisas apontam para a necessidade de se retomar com os estudantes suas visões e motivações sobre a fraude, bem como suas consequências. Para tanto, é necessário, como observou Zeichner (1993), recuperar a consideração pelo professor e seu papel na promoção da qualidade da educação.

Entendemos que a alta incidência de estudantes que admitem ter colado e outros que colam é um fato que merece atenção por parte dos educadores. Um jovem ter experimentado/praticado a cola, durante a fase de escolarização, não implica em tornar-se um fraudador contumaz, porém, como outros desafios inerentes à formação do caráter, este é mais um dentre os que pesquisadores e professores da área de educação precisam atentar.

Em uma concepção de avaliação formativa, que serve para retroalimentar o processo ensino-aprendizagem, a banalização da fraude é deplorável. Sendo assim, é pertinente que seja amplamente pesquisada, discutida e enfrentada. Para 
tanto, as instituições de Ensino Superior, ao contrário de ignorá-la, precisam refletir e encaminhar ações no sentido de compreendê-la, evitá-la e minimizá-la. Essas ações envolvem a mudança nos objetivos e nos instrumentos de avaliação, passando a valorizar a construção do conhecimento pelo estudante para a sua formação, a exemplo de seminários, entre outros - no lugar das provas de múltipla escolha -, até a definição compartilhada pela comunidade acadêmica de códigos de condutas, que efetivamente sejam respeitados. A forma como a avaliação é concebida, valorizada e realizada é determinante para a apropriação do patrimônio cultural por nossos estudantes, para a qualidade da educação e, portanto, para sua humanização.

Neste artigo, pretendemos suscitar a discussão de questões relacionadas às motivações para a prática da cola (fraude em avaliações), bem como para suas consequências. Espera-se que outras discussões contemplem o papel e a responsabilidade das instituições de ensino: o que tem sido feito e como. Além disso, cabe refletir mais sobre as implicações da fraude na qualidade da formação dos profissionais que vão atuar na sociedade. A importância desta discussão está justamente no fato de que é esta qualidade que determina a produção científica e tecnológica, a competitividade das empresas e do país, a geração de empregos e, consequentemente, a qualidade de vida dos cidadãos.

\section{Referências}

ARISTÓTELES. Ética a Nicômaco. São Paulo: Martin Claret, 2011.

ARAGÃO, Rosália Maria Ribeiro de. Tratando da indissociabilidade: ensino pesquisa extensão. São Bernardo do Campo: Unesp, 2002.

BALLESTER, Margarida et al. Avaliação como apoio à aprendizagem. Porto Alegre: Artmed, 2003.

BOGDAN, Robert; BIKLEN, Sari. Investigação qualitativa em educação: uma introdução à teoria e aos métodos. Porto: Porto Editora, 1994.

CALLAHAN, David. The cheating culture: why more americans are doing wrong to get ahead. Boston: Harcourt, 2004.

CANNELL, J.J. How public educators cheat on standardized

achievement tests: the "Lake Wobegon" Report. Albuquerque, NM: Friends for Education, 1989. 
CARDOSO, Abílio. Os Enunciados de Testes como Meios de Informação sobre o Currículo. In: ESTRELA, Albano; NÓVOA, António. Avaliações em educação: novas perspectivas. Porto: Porto Editora, 1999.

COLEMAN, James S. Academic Achievement and the Structure of

Competition. Harvard Education Review, Boston, v. 29, p. 330-351, 1959.

DAMATTA, Roberto. O que faz o brasil, Brasil? Rio de Janeiro: Rocco, 1986.

DIAS SOBRINHO, José. Campo e caminhos da avaliação: a avaliação da educação superior no Brasil. In: FREITAS, Luis C. (Org.). Avaliação: construindo o campo e a crítica. Florianópolis: Insular, 2002.

DOMINGUES, Ivo. O copianço na universidade: o grau zero na qualidade. Lisboa: Media XXI, 2006.

ECKSTEIN, Max A. Combating academic fraud towards a culture of integrity. Paris: International Institute of Educational Planning/UNESCO, 2003.

FERNANDES, Domingos. Para uma teoria da avaliação formativa. Revista Portuguesa de Educação, Lisboa, v. 19, n. 2, p. 21-50, 2006.

FREIRE, Paulo. Pedagogia do oprimido. Rio de Janeiro: Paz e Terra, 1974.

FREIRE, Paulo. Pedagogia da autonomia: saberes necessários à prática educativa. Rio de Janeiro: Paz e Terra, 1996.

FREITAS, Luís Carlos (Org.). Avaliação: construindo o campo e a crítica. Florianópolis: Insular, 2002.

FRIAS, Maria Cristina; BENCINI, Roberta. Professores brasileiros precisam aprender a ensinar. Jornal da Ciência, São Paulo, set. 2009. Disponível em: $<$ http://www.jornaldaciencia.org.br/Detalhe.jsp?id=65279>. Acesso em: 12 ago. 2010.

GIDDENS, Anthony. As consequências da modernidade. São Paulo: Editora UNESP, 1991.

GOMES, Carlos Alberto. Ética e justiça na avaliação: a fraude e o 'copianço' no processo ensino/aprendizagem. Educação \& Linguagem, São Paulo, v. 11, n. 17, p. 147-159, jan/jun, 2008. 
GREEN, Stuart P. Cheating. Law and Philosophy, Netherlands, v. 23, n. 2, p. 137-185, 2004.

HADJI, Charles. Avaliação desmistificada. Porto Alegre: Artmed, 2001. JORBA, Jaume; SANMARTI, Neus. A função pedagógica da avaliação. In: BALLESTER, Margarida et al. Avaliação como apoio à aprendizagem. Porto Alegre: Artmed, 2003.

JORDAN, A. E. College student cheating: the role of motivation, perceived, norms, attitudes, and knowledge of institutional policy. Ethics \& Behavior, Estados Unidos da América, v. 11, n. 3, p. 233-247, 2001.

KLEIN, Helen A. et al. Cheating during the college years: how do Business School students compare? Journal of Business Ethics, Estados Unidos da América, v. 72, n. 2, p. 197-206, maio 2007.

LA TAILLE, Yves de. A questão da indisciplina: ética, virtudes e educação. In: DEMO, Pedro; LA TAILLE, Yves de; HOFFMANN, Jussara. Grandes pensadores em educação: o desafio da aprendizagem, da formação moral e da avaliação. 4. ed. Porto Alegre: Mediação, 2008.

LAWSON, R. A. Is classroom cheating related to business students' propensity to cheat in the "Real World"? Journal of Business Ethics, Estados Unidos da América, v. 49, n. 2, p. 189-199, jan. 2004.

LIMA, Licínio C. O paradigma da educação contábil Políticas educativas e perspectivas gerencialistas no ensino superior em Portugal. Revista Brasileira de Educação, Brasil, n. 4, p. 43-59, jan./abr. 1997.

LUCKESI, Cipriano Carlos. Avaliação da aprendizagem escolar: estudos e proposições. São Paulo: Cortez, 2003.

MARAMAK, S.; MALINE, M.B. Academic dishonesty among college students: issues in education. Washington, DC: Office of Research, 1993.

MCCABE, Donald L.; TREVINO, Linda K.; BUTTERFIELD, Kenneth D. The influence of collegiate and corporate codes of conduct on ethics-related behavior in the workplace. Business Ethics Quarterly, Reino Unido, v. 6, n. 4, p. 461-476, 1996.

MIZUKAMI, Maria da Graça Nicoletti. Docência, trajetórias pessoais e desenvolvimento profissional. In: REALI, Alina Maria de Medeiros 
Rodrigues; MIZUKAMI, Maria da Graça Nicoletti. (Orgs.). Formação de professores - tendências atuais. São Carlos: EDUFSCar, 1996.

NURJOLBER. Kyrgyz Republic: Addressing corruption in theeEducation Sector in Narynskaya Oblast. Naranskaya Oblast: Partnership for Transparency Fund, 2008.

PASSOW, Honor J. et al. Factors influencing engineering students' decisions to cheat by type of assessment. Research in Higher Education, Países Baixos, v. 47, n. 6, set 2006.

PAULSEN, Sandra. O problema da cola: cartas de Estocolmo. Postado no Blog do Noblat. 30 jan. 2009. Disponível em: <http://oglobo.globo.com/pais/ noblat/posts/2009/01/30/o-problema-da-cola-157509.asp>. Acesso em: 22 de ago. 2009.

PERRENOUD, Philippe. Avaliação: da excelência à regulação das aprendizagens - entre duas lógicas. Porto Alegre: Artes Médicas Sul, 1999.

PERRENOUD, Philippe. 10 novas competências para ensinar. Porto Alegre: Artes Médicas, 2000.

QUINQUER, Dolors. Modelos e enfoques sobre a avaliação: o modelo comunicativo. In: BALLESTER, Margarida et al. Avaliação como apoio à aprendizagem. Porto Alegre: Artmed, 2003.

SAVATER, Fernando. Ética para meu filho. 2. ed. São Paulo: Martins Fontes, 2002.

SILVA, Gabriela Andrade da et al. Um estudo sobre a prática da cola entre universitários. Psicol. Reflex. Crit., Porto Alegre, v. 19, n. 1, p. 18-24, 2006. Available from <http://www.scielo.br/scielo.php?script=sci arttext\&pid=S0102-79722006000100004\&lng=en\&nrm=iso $>$. Access on: 18 Apr. 2015.

SOUSA, Clarilza Prado (Org.). Avaliação do rendimento escolar. Campinas: Papirus, 1991.

SOUSA, Sandra Zakia Lian. Revisando a teoria da avaliação da aprendizagem. In: SOUSA, C. P. (Org.). Avaliação do rendimento escolar. Campinas, SP: Papirus, 1991. 
VASCONCELLOS, C. dos S. Avaliação: concepção dialética-libertadora do processo de avaliação escolar. São Paulo: CS Vasconcellos, 1993. (Cadernos Pedagógicos do Libertad, v. 3).

VAZQUEZ, Adolfo Sánchez. Ética. Rio de Janeiro: Civilização Brasileira, 2012.

WAISELFISZ, Julio J. Relatório de desenvolvimento juvenil. Brasília, DF: Instituto Sangari; MCT, 2007.

WHITLEY JR, B. E. Factors associated with cheating Among college students: a review. Research in Higher Education, Países Baixos, v. 39, n. 3, p. 235-274, 1998.

ZEICHNER, Kenneth M. A formação reflexiva de professores: idéias e práticas. Lisboa: Educa, 1993.

Maria Alzira de Almeida Pimenta - Universidade de Sorocaba Sorocaba | SP | Brasil. Contato: alzira.pimenta@gmail.com br

Sônia de Almeida Pimenta - Universidade Federal da Paraíba João Pessoa | PB | Brasil. Contato: sopimenta1@gmail.com

Artigo recebido em 18 de abril de 2015 e aprovado em 19 de outubro de 2015. 